\title{
Biodiesel Production from Methanolysis of Lard Using CaO Catalyst Derived from Eggshell: Effects of Reaction Time and Catalyst Loading
}

\author{
Luqman Buchori ${ }^{1, *}$, Didi Dwi Anggoro ${ }^{1}$, Anwar Ma'ruf ${ }^{2}$ \\ ${ }^{1}$ Department of Chemical Engineering, Faculty of Engineering, Diponegoro University, Jl. Prof. Soedarto, SH, Tembalang, Semarang \\ 50275, Indonesia
}

${ }^{2}$ Department of Chemical Engineering, Faculty of Engineering and Science, Muhammadiyah University of Purwokerto, Jl. Raya Dukuh Waluh, Purwokerto 53182, Indonesia

\begin{tabular}{l} 
A R T I C L E I N F O \\
\hline Article history: \\
Received: 25 January, 2021 \\
Accepted: 06 March, 2021 \\
Online: 17 March, 2021 \\
\hline Keywords: \\
Biodiesel \\
CaO Catalyst \\
Lard \\
\end{tabular}

\begin{abstract}
A B S T R A C T
Biodiesel was produced from lard using a CaO catalyst derived from eggshells. The effects of catalyst loading and transesterification reaction time were investigated. The results revealed that the increase in yield of biodiesel occurred at all catalyst loading when the reaction time was increased. The optimal reaction time was obtained at 60 minutes. The results also indicated that there was an increase in yield of biodiesel when the catalyst loading was increased from $0.5 \%$ to $1 \%$. Furthermore, increases in catalyst loading decreased biodiesel yields. The most optimum biodiesel yield of $92.69 \%$ was achieved when the reaction time, catalyst loading, methanol:oil molar ratio, reaction temperature, and pressure were 60 minutes, $1 \%, 6: 1,65^{\circ} \mathrm{C}$, and $1 \mathrm{~atm}$, respectively. The FAME content in biodiesel product was $95.28 \%$. The biodiesel obtained reflected a cetane number and heating value of 46.2 and $37.86 \mathrm{MJ} / \mathrm{kg}$, respectively. Eggshell-derived $\mathrm{CaO}$ catalysts exhibited excellent reusability.
\end{abstract}

\section{Introduction}

Biodiesel is currently being developed as an alternative fuel on account of its many advantages over diesel oil, which include nontoxicity, environmentally friendly, biodegradability, high cetane number, and low emission $[1,2]$. Biodiesel is a renewable resource composed of a mixture of various FAAE (fatty acid alkyl esters). Biodiesel, as a renewable alternative energy, can be made from vegetable oils and animal fats as a source of raw materials [3, 4]. Biodiesel can be obtained by esterification or transesterification process. Esterification process is the reaction of FFA (free fatty acids) with alcohol to produce FAME (fatty acid methyl ester) and water [5]. Transesterification is a reaction between triglycerides that can be obtained from oil derived from plants or fats from animals with alcohol to produce FAME and glycerol as a byproduct $[6,7]$. Esterification is carried out if the FFA content of the raw materials is higher than $2 \%$ [8,9]. If the FFA content $<1 \%$, biodiesel synthesis is carried out by transesterification only.

Of the various types of vegetable oils, the most commonly used to produce biodiesel include rapeseed oil (in Canada), sunflower

*Corresponding Author: Luqman Buchori, Email: luqman.buchori@che.undip.ac.id oil (in Southern Europe), soybean oil (in the United States), palm oil (in South Asian countries, especially Malaysia. and Indonesia), as well as castor oil (in India) $[5,10]$. The utilization of animal fats as feedstock for biodiesel production has also been previously studied. Among the animal fats studied were lard, beef tallow, and fish oil $[11,12]$. Compared to vegetable oils, biodiesel from animal fats shows several advantages, including high calorific value and cetane number [10]. However, biodiesel from animal fats also shows disadvantages, including high saturated fatty acid contents, plugging points and cold filter clouding point, which can cause problems during winter operations $[11,13]$.

Biodiesel synthesis from lard has been studied by several researchers [11, 13-18]. In [11] and [15], for example, the authors used $\mathrm{KOH}$ as a catalyst and produced biodiesel with FAME contents of $88.7 \%$ and $99.4 \%$, respectively. In [18], the authors also used catalysts of $1.25 \% \mathrm{KOH}$ and obtained a FAME yield of $96 \%$. The biodiesel production from a mixture of soybean oil and lard using $\mathrm{NaOH}$ catalyst has been studied [13], which obtained a biodiesel yield of $77.8 \%$. In [14], the authors investigated the transesterification of refined lard. The research was carried out in supercritical methanol. In this work, the transesterification process 
is carried out under reaction temperature conditions of $320-350{ }^{\circ} \mathrm{C}$, reaction time of 5-20 min, methanol:oil molar ratio of 30-60, pressure of 15-25 $\mathrm{MPa}$, and agitation speed of $0-1000 \mathrm{rpm}$. The results revealed a FAME yield of $89.91 \%$. In [16], the authors explored the synthesis of biodiesel using immobilized C. antarctica lipase B as a biocatalyst. The biodiesel yield of $96.8 \%$ was obtained by a ultrasonic amplitude of $5 \mathrm{kHz}$, reaction time of 20 min, 1:4 molar ratio of fat:methanol and $6 \%(\mathrm{w} / \mathrm{w}$ of fat) catalyst level. Meanwhile, $\mathrm{CaO}$ as a catalyst has also been used in production of biodiesel by waste lard methanolysis [17].

In general, in the transesterification process, the researchers used a homogeneous catalyst in the biodiesel production from lard. The utilization of heterogeneous catalysts in the transesterification process, especially $\mathrm{CaO}$, has not been widely developed by researchers. Calcium oxide is one of the most active and potential solid catalysts in the transesterification process. This catalyst can be reused, recyclable, inexpensive, non-corrosive, and environment-friendly; moreover, in methanol has low solubility, and a catalyst with high activity for the methanolysis reaction of oil $[19,20]$. CaO can be obtained from calcination of waste shells, such as eggshells [21]. The utilization of eggshell as a catalyst in the production of biodiesel from lard has not been widely studied by researchers. Therefore, it is necessary to develop biodiesel production from waste shell, especially eggshells.

The aims of this study were to produce biodiesel from lard using $\mathrm{CaO}$ from eggshells as a heterogeneous catalyst, and to determine the effect of catalyst loading and transesterification reaction time. The characteristics of the biodiesel produced, including its density, cetane number, kinematic viscosity, and heating value, were then studied and compared with those of a biodiesel standard.

\section{Experimental Methods}

\subsection{Materials}

Methanol (99.9\%, Merck) and lard were used as raw materials for biodiesel synthesis. Lard was purchased from a Johar market, Semarang, Indonesia. The reagent used for esterification was $\mathrm{HCl}$ (37\%, Merck). $\mathrm{CaO}$ was prepared from eggshells obtained from restaurant waste around Tembalang, Semarang, Indonesia.

\subsection{Catalyst Preparation}

The eggshells obtained from the restaurant were rinsed using running water, and then cleaned with distilled water to eliminate dust and dirt. The clean eggshells were then dried in an oven (Memmert UN 55 B214.0281, Germany) at $105^{\circ} \mathrm{C}$ overnight. Dry eggshells were crushed and calcined for $4 \mathrm{~h}$ in air in a Ney Vulcan muffle furnace (Vulcan Bench Top Furnace model D-550-240V) at $900{ }^{\circ} \mathrm{C}$. The product obtained was $\mathrm{CaO}[21,22]$ as a white powder.

\subsection{Biodiesel Synthesis Using Esterification and Transesterification Process}

Biodiesel synthesis was carried out by esterification and transesterification processes. Both processes were completed in a three-necked flask (Pyrex). This equipment was connected with a reflux condenser (Pyrex) and heater. Esterification aims to reduce the FFA content in lard. Methanol and oil were added to the three- necked flask at 6:1 methanol to oil molar ratio. Thereafter, $\mathrm{HCl}$ amounting to $0.75 \% \mathrm{w} / \mathrm{w}$ of oil was added to the flask. The mixture was then stirred with a magnetic stirrer (Model No. SP131320-33 $240 \mathrm{~V}$, Thermo Scientific) at $400 \mathrm{rpm}$ while heating to $65^{\circ} \mathrm{C}$. Esterification was performed for $2 \mathrm{~h}$. The esterification product was placed into a separating funnel and allowed to settle overnight. The product was then collected from the remaining methanol and acid catalyst.

The esterified lard was then reacted with methanol in a threeneck flask with methanol to oil molar ratio of 6:1. A number of $\mathrm{CaO}$ catalyst was loaded into the three-neck flask. Then, the mixture was reacted at $65{ }^{\circ} \mathrm{C}$ while stirring at $400 \mathrm{rpm}$. After the transesterification process was completed, the product was placed into a separating funnel (Pyrex) to be separated from the catalyst. The product was allowed to settle overnight to separate the biodiesel from excess methanol and glycerol. The glycerol at the bottom of the funnel was withdrawn, and the excess methanol in the top biodiesel layer was removed. Yield of biodiesel was determined by using (1);

$$
\text { Yield }(\%)=\frac{\text { weight of biodiesel product }(g)}{\text { weight of lard }(g)} \times 100 \%
$$

Variables influencing the transesterification process, such as catalyst loading $(0.5-7 \%)$ and reaction time (30-120 min), were also studied.

\section{Results and Discussion}

\subsection{Esterification Result}

During biodiesel synthesis, raw materials with high FFA contents require a two-step process, namely esterification and transesterification $[7,8]$. In general, lard has an FFA content higher that $1 \%$ [16]; in fact, the raw materials analysis showed that the FFA content of lard was $10.05 \%$. Thus, esterification is needed to decrease the FFA content of the raw material. The esterification process can decrease the FFA content of lard to $1.36 \%$. To produce biodiesel, transesterification is then carried out.

\subsection{Biodiesel Production Via Transesterification}

\subsubsection{Effect of transesterification reaction time}

The effect of transesterification reaction time on biodiesel yield was investigated. The reaction time is an important parameter in biodiesel production [8]. The effect of reaction time on biodiesel yield can indicate the costs involved in producing biodiesel [23]. Here, transesterification reaction times of 30, 60, 90 , and 120 minutes were applied. The experimental results were shown in Figure 1.

Figure 1 presents an increase in yield of biodiesel at all catalyst loadings and reaction times of 30-60 minutes. At the reaction time of 30 minutes with $1 \%$ catalyst loading, the biodiesel obtained was only $75.3 \%$. This shows that at the reaction time of 30 minutes, the transesterification reaction has not reached equilibrium. This means that not all reactants have enough time to interact both between reactants and with the catalyst, resulting in lower biodiesel. Biodiesel yield increased and achieved its optimum at reaction time of 60 minutes. The optimum biodiesel yield was $92.69 \%$. The experimental results reveal that a reaction time of 30 minutes is insufficient to complete the transesterification process. 
Furthermore, at the reaction time after 60 minutes, there was a slight increase in the yield of biodiesel and it became almost constant. The increase in biodiesel yield is not significant. These results indicate that a reaction time of 60 minutes is sufficient to produce an effective biodiesel production.

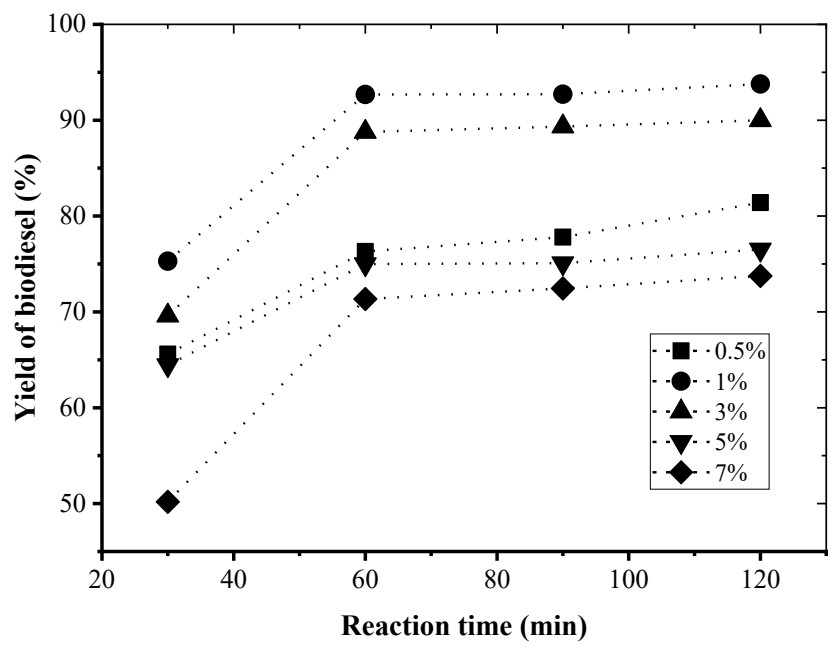

Figure 1: Effect of transesterification reaction time on yield of biodiesel under various catalyst loadings (methanol:oil $=6: 1 ; \mathrm{P}=1 \mathrm{~atm} ; \mathrm{T}=65^{\circ} \mathrm{C}$ )

The study conducted by previous researchers [15] also found that the optimal reaction time for production of biodiesel from lard was 60 minutes. In this study, the biodiesel yield obtained in the transesterification step was $97.2 \%$ at a $\mathrm{KOH}$ concentration of $2 \%$ wt and the ratio of methanol to oil was 9:1. In [17], the authors used a $\mathrm{CaO}-$ based catalyst from piglet roasting and quicklime during biodiesel production from waste lard and obtained a yield of $97.6 \%$ within 60 minutes. This finding reveals that the average transesterification reaction time needed for biodiesel production from lard via conventional methods was 60 minutes. Meanwhile, biodiesel production using supercritical methanol required 15 minutes of reaction to achieved 89.91\% FAME content [14].

\subsubsection{Effect of catalyst loading}

The effect of catalyst loading on the transesterification process was studied by varying the $\mathrm{CaO}$ contents to $0.5,1,3,5$, and $7 \%$ $(\mathrm{w} / \mathrm{w})$ of lard with $6: 1$ methanol to oil ratio for $1 \mathrm{~h}$ at $65^{\circ} \mathrm{C}$. The resulting yield of biodiesel were presented in Figure 2.

Figure 2 shows that biodiesel yields increase when catalyst loading is increased from 0.5 to $1 \%$. Furthermore, the higher the catalyst loading, the lower the biodiesel yield. The high catalyst concentration causes the mixture in the reactor to become too viscous. This fact results in more mass transfer resistance and therefore, perhaps some of the catalysts remain unused, which in turn lowers biodiesel yield [24]. In this study, an increase in catalyst amount causes the formation of a slurry from the mixing of the catalyst and reactants. The larger the amount of catalyst added to the reaction system, the more viscous the mixture becomes. As a result, higher power consumption is needed during the stirring process. Increased viscosity due to slurry formation must be prevented because it causes yield of biodiesel to decrease. In order for this problem to be avoided, it is necessary to determine the optimum amount of catalyst loading. The increase in viscosity can also cause a slight soap formation which hinders the reaction process resulting in a decrease in yield. The results reveal that the optimum catalyst loading in this study is $1 \%$.

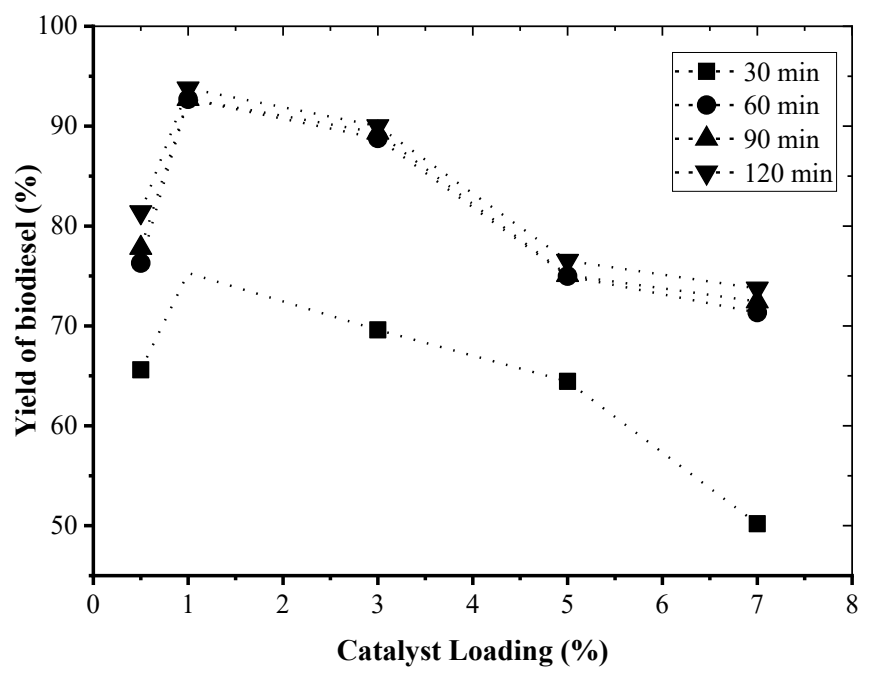

Figure 2: Effect of catalyst loading on biodiesel yield at various reaction times (methanol:oil $=6: 1 ; \mathrm{P}=1 \mathrm{~atm} ; \mathrm{T}=65^{\circ} \mathrm{C}$ )

Works that have been done in previous studies also indicated the same results $[11,18]$. In [11], the authors applied $\mathrm{KOH}$ as a catalyst. The concentration of $\mathrm{KOH}$ varied at $0.6 \%, 0.9 \%$ and $1.2 \%$. The results showed that the optimum biodiesel product with a FAME content of $88.73 \%$ was achieved at $0.9 \%$ wt $\mathrm{KOH}$ with a reaction temperature of $60{ }^{\circ} \mathrm{C}$, a methanol-lard mole ratio of $6: 1$, and a stirring speed of $600 \mathrm{rpm}$. Meanwhile, in [18], the authors performed the optimization of lard oil methanolysis using a potassium hydroxide catalyst. The results showed that the optimum biodiesel yield was $96.2 \%$ at the amount of catalyst $1.25 \%$ under the following conditions: reaction temperature of $60{ }^{\circ} \mathrm{C}$, reaction time of $40 \mathrm{~min}$, the molar ratio of methanol to oil was $6: 1$, and stirring speed of $250 \mathrm{rpm}$.

\subsubsection{FAME content of the biodiesel product}

Optimal biodiesel production occurs under a reaction time of 60 minutes and $1 \% \mathrm{wt}$ catalyst loading; these conditions produce an optimum biodiesel yield of $92.69 \%$. The biodiesel product produced at these optimum conditions was analyzed using GCMS (gas chromatography-mass spectrometry) (QP2010S SHIMADZU, DB-1 column) to determine its composition, and the results are presented in Table 1 . The biodiesel obtained contained approximately 24 compounds, 15 of which were methyl esters.

Table 1: Composition of the biodiesel product

\begin{tabular}{|c|c|c|l|}
\hline Peak & $\begin{array}{c}\text { Retention } \\
\text { time }\end{array}$ & $\begin{array}{c}\text { Composition } \\
(\%)\end{array}$ & \multicolumn{1}{|c|}{ Name } \\
\hline 1 & 20.276 & 0.02 & $\begin{array}{l}\text { Decanoic acid, methyl ester } \\
\text { (CAS) }\end{array}$ \\
\hline 2 & 26.907 & 0.19 & $\begin{array}{l}\text { Dodecanoic acid, methyl ester } \\
\text { (CAS) }\end{array}$ \\
\hline 3 & 32.676 & 0.95 & $\begin{array}{l}\text { Tetradecanoic acid, methyl ester } \\
\text { (CAS) }\end{array}$ \\
\hline 4 & 35.299 & 0.04 & $\begin{array}{l}\text { Pentadecanoic acid, methyl ester } \\
\text { (CAS) }\end{array}$ \\
\hline
\end{tabular}


L. Buchori et al. / Advances in Science, Technology and Engineering Systems Journal Vol. 6, No. 2, 399-404 (2021)

\begin{tabular}{|c|c|c|c|}
\hline 5 & 37.186 & 0.18 & $\begin{array}{l}\text { 9-Hexadecenoic acid, methyl } \\
\text { ester, (Z)- (CAS) }\end{array}$ \\
\hline 6 & 37.312 & 0.67 & $\begin{array}{l}\text { 9-Hexadecenoic acid, methyl } \\
\text { ester, (Z)- (CAS) }\end{array}$ \\
\hline 7 & 38.035 & 22.08 & $\begin{array}{l}\text { Hexadecanoic acid, methyl ester } \\
\text { (CAS) }\end{array}$ \\
\hline 8 & 38.778 & 0.03 & Pentadecanoic acid (CAS) \\
\hline 9 & 39.658 & 0.09 & $\begin{array}{l}\text { 9-Octadecenoic acid (Z)-, methyl } \\
\text { ester (CAS) }\end{array}$ \\
\hline 10 & 39.914 & 0.19 & $\begin{array}{l}\text { Heptadecanoic acid, methyl ester } \\
\text { (CAS) }\end{array}$ \\
\hline 11 & 41.888 & 11.07 & $\begin{array}{l}\text { 9,12-Octadecadienoic acid (Z,Z)-, } \\
\text { methyl ester (CAS) }\end{array}$ \\
\hline 12 & 43.118 & 53.75 & $\begin{array}{l}\text { 9-Octadecenoic acid (Z)-, methyl } \\
\text { ester (CAS) }\end{array}$ \\
\hline 13 & 43.634 & 5.47 & $\begin{array}{l}\text { Octadecanoic acid, methyl ester } \\
\text { (CAS) }\end{array}$ \\
\hline 14 & 44.198 & 0.05 & $\begin{array}{l}\text { 9-Hexadecenoic acid, methyl } \\
\text { ester, (Z)- (CAS) }\end{array}$ \\
\hline 15 & 45.396 & 0.18 & Methyl arachidonate \\
\hline 16 & 45.776 & 0.16 & $\begin{array}{l}\text { 7,10,13-Eicosatrienoic acid, } \\
\text { methyl ester (CAS) }\end{array}$ \\
\hline 17 & 46.186 & 1.95 & Tridecanedial \\
\hline 18 & 46.796 & 0.37 & $\begin{array}{l}\text { Eicosanoic acid, methyl ester } \\
\text { (CAS) }\end{array}$ \\
\hline 19 & 49.475 & 0.14 & $\begin{array}{l}\text { 5,8,11,14-Eicosatetraenoic acid, } \\
\text { ethyl ester, (all-Z)- (CAS) }\end{array}$ \\
\hline 20 & 49.773 & 1.16 & Di-(9-octadecenoyl)-glycerol \\
\hline 21 & 50.414 & 0.65 & $\begin{array}{l}\text { Hexadecanoic acid, 2-hydroxy-1- } \\
\text { (hydroxymethyl) ethyl ester (CAS) }\end{array}$ \\
\hline 22 & 53.237 & 0.05 & $\begin{array}{l}\text { 3-(Dideuteromethoxymethoxy)- } \\
\text { 2,3-Dimethyl-1-Undecene }\end{array}$ \\
\hline 23 & 54.075 & 0.48 & $\begin{array}{l}\text { 9-Octadecenoic acid (Z)-, 9- } \\
\text { octadecenyl ester, (Z)- (CAS) }\end{array}$ \\
\hline \multirow[t]{2}{*}{24} & 69.515 & 0.09 & $\begin{array}{l}\text { Cholest-5-en-3-ol (3.beta.)- } \\
\text { (CAS) }\end{array}$ \\
\hline & & 100.00 & \\
\hline
\end{tabular}

injected into the combustion chamber is influenced by the density of the fuel. Likewise, the air-fuel ratio is influenced by the density of the fuel. In the same volume, a denser fuel contains a greater mass. It means that a high density contains a high mass. Meanwhile, the fuel injection pump measures fuel by volume rather than by mass. Therefore, if the fuel density is too high it will affect the performance of the injection pump, as a result the combustion process becomes incomplete. The density obtained in this study has met biodiesel standards with the minimum standard of density being $0.860 \mathrm{~g} / \mathrm{cm} 3$ and a maximum of $0.900 \mathrm{~g} / \mathrm{cm} 3$.

Table 2: Composition of the biodiesel product

\begin{tabular}{|c|c|c|c|c|}
\hline Fuel property & Units & Standard & Method & $\begin{array}{c}\text { Experimenta } \\
\text { values }\end{array}$ \\
\hline $\begin{array}{l}\text { Density } \\
\left(25^{\circ} \mathrm{C}\right)\end{array}$ & $\mathrm{g} / \mathrm{cm}^{3}$ & $\begin{array}{c}0.860 \text { to } \\
0.900\end{array}$ & $\begin{array}{c}\text { EN ISO } \\
3675[26]\end{array}$ & 0.860 \\
\hline $\begin{array}{l}\text { Kinematic } \\
\text { viscosity } \\
\left(40^{\circ} \mathrm{C}\right)\end{array}$ & $\mathrm{mm}^{2} / \mathrm{s}$ & 1.9 to 6.0 & $\begin{array}{c}\text { ASTM } \\
\text { D445-19 } \\
{[27]}\end{array}$ & 4.48 \\
\hline $\begin{array}{l}\text { Cetane } \\
\text { number }\end{array}$ & - & $47(\mathrm{~min})$ & $\begin{array}{c}\text { ASTM } \\
\text { D613-18a } \\
{[28]}\end{array}$ & 46.2 \\
\hline Heating value & $\mathrm{MJ} / \mathrm{kg}$ & 39.72 & $\begin{array}{c}\text { ASTM } \\
\text { D240-19 } \\
{[29]}\end{array}$ & 37.86 \\
\hline
\end{tabular}

Table 2 indicates that the kinematic viscosity of the biodiesel product obtained in this study is between the minimum and maximum standards of biodiesel. Viscosity is an important parameter of the biodiesel fuel produced. Viscosity affects the quality of atomization [4]. High viscosity can lead to poor atomization process. The viscosity of the fuel also affects droplet size. High viscosity has the potential to produce larger droplets at the time of injection so that the atomization process is disturbed, as a result of which the spraying becomes poor. Poor atomization results in poor combustion which increases exhaust fumes and fuel emissions. Fuels with high viscosity also result in the need for more energy to pump fuel and can cause deposits in the engine. The kinematic experimental value of the viscosity produced in this study was $4.48 \mathrm{~mm}^{2} / \mathrm{s}$. This value is still below the maximum value required by the ASTM D445-19 specification $\left(6.0 \mathrm{~mm}^{2} / \mathrm{s}\right)$.

The cetane number, defined by ASTM D613-18a, is a measure of the auto-ignition delay time of the fuel. Diesel engines desirable high cetane numbers. A higher cetane number results in a shorter time between ignition and initiation of the fuel injection. The high cetane number also ensures the engine is started and running properly and smoothly. In contrast, a low cetane number causes incomplete combustion which tends to increase gas and particulate emissions which in turn result in air pollution. The cetane number value generated in this work is 46.2. This cetane number is slightly lower than the minimum biodiesel standard required, which is 47 . This is probably due to the double bonds of fatty acid compounds. Compounds with double bonds can cause a lower cetane number [30]. The results of GC-MS analysis show that the biodiesel product obtained contains several compounds with double chains, such as 9,12-octadecadienoic acid and 9octadecenoic acid, which could reduce its cetane number.

Table 2 also reveals that the heating value of the biodiesel obtained in this study is $37.86 \mathrm{MJ} / \mathrm{kg}$. The heating value describes 402 
the amount of heat produced from the fuel combustion with oxygen [4]. At the initial temperature, this combustion produces $\mathrm{CO}_{2}$ and $\mathrm{H}_{2} \mathrm{O}$. The higher the heating value, the less the amount of fuel needed to produce combustion heat. Thus, the higher the heating value, the more efficient the use of fuel. Increasing the amount of carbon in the fuel molecule will increase the heating value of the fuel. The increase in heating value is in line with the increasing ratio of carbon and hydrogen to oxygen and nitrogen [4]. The heating value of the biodiesel product obtained in this work is approximately $4.68 \%$ less than that of biodiesel standard and $11 \%$ less than petrodiesel, which has a heating value of 42.7 $\mathrm{MJ} / \mathrm{kg}$.

\subsection{Catalyst Reusability}

One method to determine the stability of a heterogeneous catalyst is to test the recyclability of the catalyst. The reusability of the catalyst was carried out in conditions where the transesterification process produced optimum biodiesel yield, namely the reaction temperature of $65{ }^{\circ} \mathrm{C}$, the mole ratio of methanol: lard of $6: 1$, the catalyst loading of $1 \%$ and the reaction time of $1 \mathrm{~h}$. The catalyst that has been used in each cycle was separated by filtering and then washed with methanol to remove adsorbed material. The catalyst was then recalcined at $900{ }^{\circ} \mathrm{C}$ for further use. The results of the catalyst reusability were shown in Figure 3.

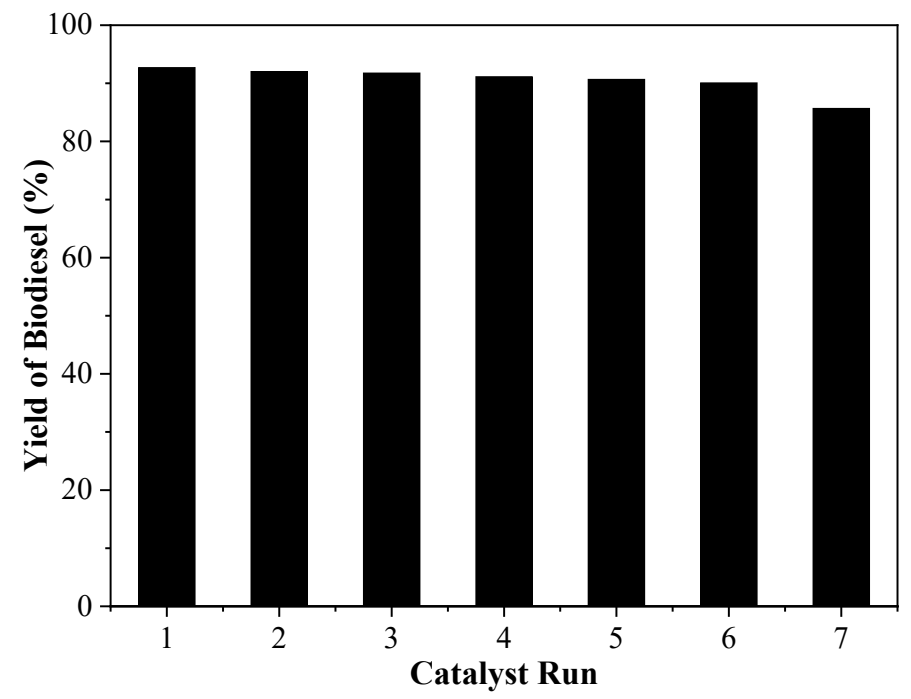

Figure 3: Effect of catalyst reusability on biodiesel yield (methanol:oil $=6: 1 ; \mathrm{P}=$ $1 \mathrm{~atm} ; \mathrm{T}=65^{\circ} \mathrm{C}$; catalyst loading $=1 \%$, reaction time $=60 \mathrm{~min}$ )

Figure 3 shows that the biodiesel yield decreases with increasing catalyst use cycles. Nevertheless, the catalyst can be reused after six consecutive runs with excellent activity in the lard transesterification reaction for biodiesel production. The biodiesel yield obtained was still above $90 \%$. However, in the seventh run the biodiesel yield was found to have decreased below $90 \%$, which was $85.67 \%$. The decrease in biodiesel yield after each run may be due to the blocking of the active sites on the catalyst surface by the deposition of unreacted oil, biodiesel or glycerol [24]. These results indicate that the $\mathrm{CaO}$ catalyst derived from eggshells has a high potential to be used as a catalyzing for biodiesel production with good reusability.

\section{Conclusion}

Biodiesel can be obtained from lard in high yields. The reaction time of transesterification required to obtain biodiesel is only 60 minutes with $1 \% \mathrm{wt}$ catalyst loading. The biodiesel yield produced from this study was $92.69 \%$ with the FAME content was $95.28 \%$. The fuel properties of biodiesel products that meet the established standards are kinematic viscosity and density. Meanwhile, the heating value and cetane number obtained in this work are slightly lower than those of the biodiesel standard. In the transesterification process, the $\mathrm{CaO}$ catalyst derived from eggshells is able to maintain its catalytic activity after being reused 7 times. The results generally prove that biodiesel synthesis from lard using a heterogeneous catalyst, specifically $\mathrm{CaO}$ from eggshell, is an acceptable strategy.

\section{Conflict of Interest}

The authors declare no conflict of interest.

\section{Acknowledgment}

We would like to thank the Faculty of Engineering, Diponegoro University, Indonesia who financially supported this research through the Strategic Research Grant.

\section{References}

[1] Ü. Ağbulut, S. Sarıdemir, S. Albayrak, "Experimental investigation of combustion, performance and emission characteristics of a diesel engine fuelled with diesel-biodiesel-alcohol blends," Journal of the Brazilian Society of Mechanical Sciences and Engineering, 41(389), 1-12, 2019, doi:10.1007/s40430-019-1891-8.

[2] L. Buchori, I. Istadi, P. Purwanto, "Synthesis of biodiesel on a hybrid catalytic-plasma reactor over $\mathrm{K}_{2} \mathrm{O} / \mathrm{CaO}-\mathrm{ZnO}$ Catalyst," Scientific Study \& Research Chemistry \& Chemical Engineering, Biotechnology, Food Industry, 18(3), 303-318, 2017.

[3] L.T. Vargas-Ibáñez, J.J. Cano-Gómez, P. Zwolinski, D. Evrard, "Environmental assessment of an animal fat based biodiesel: Defining goal, scope and life cycle inventory," Procedia CIRP, 90, 215-219, 2020, doi:10.1016/j.procir.2020.02.053.

[4] L.F. Ramírez-Verduzco, J.E. Rodríguez-Rodríguez, A.D.R. Jaramillo-Jacob, "Predicting cetane number, kinematic viscosity, density and higher heating value of biodiesel from its fatty acid methyl ester composition," Fuel, 91(1), 102-111, 2012, doi:10.1016/j.fuel.2011.06.070.

[5] H. Trinh, S. Yusup, Y. Uemura, "Optimization and kinetic study of ultrasonic assisted esterification process from rubber seed oil”, Bioresource Technology, 247, 51-57, 2018, doi:10.1016/j.biortech.2017.09.075.

[6] T.M.I. Mahlia, Z.A.H.S. Syazmi, M. Mofijur, A.E.P. Abas, M.R. Bilad, H.C. Ong, A.S. Silitonga, "Patent landscape review on biodiesel production: Technology updates," Renewable and Sustainable Energy Reviews, 118 109526, 2020, doi:10.1016/j.rser.2019.109526.

[7] L. Buchori, I. Istadi, P. Purwanto, "Advanced chemical reactor technologies for biodiesel production from vegetable oils - A review," Bulletin of Chemical Reaction Engineering \& Catalysis, 11(3), 406-430, 2016, doi:10.9767/bcrec.11.3.490.406-430.

[8] K. Devaraj, M. Veerasamy, S. Aathika, Y. Mani, A. Thanarasu, A. Dhanasekaran, Subramanian, S, "Study on effectiveness of activated calcium oxide in pilot plant biodiesel production," Journal of Cleaner Production, 225, 18-26, 2019, doi:10.1016/j.jclepro.2019.03.244.

[9] E.G. Al-Sakkari, O.M. Abdeldayem, S.T. El-Sheltawy, M.F. Abadir, A. Soliman, E.R. Rene, I. Ismail, "Esterification of high FFA content waste cooking oil through different techniques including the utilization of cement kiln dust as a heterogeneous catalyst: A comparative study," Fuel, 279, 1-11, 2020, doi:10.1016/j.fuel.2020.118519.

[10] A. Nicolici, C. Pana, N. Negurescu, A. Cernat, C. Nutu, "The use of animal fats in the diesel fuelled engine", IOP Conference Series: Materials Science and Engineering, 444 (7), 1-8, 2018, doi:10.1088/1757-899X/444/7/072003.

[11] M. Berrios, M.C. Gutiérrez, M.A. Martín, A. Martín, "Application of the factorial design of experiments to biodieselbedevas production from lard," 
Fuel Processing Technology, 90(12), 1447-1451, 2009, doi:10.1016/j.fuproc.2009.06.026.

[12] A. Sander, M.A. Koscak, D. Kosir, N. Milosavljević, J.P. Vukovic, L. Magic, "The influence of animal fat type and purification conditions on biodiesel quality," Renewable Energy, 118, 752-760. 2018, doi:10.1016/j.renene.2017.11.068.

[13] J.M. Dias, M.C.M. Alvim-Ferraz, M.F. Almeida, "Production of biodiesel from acid waste lard," Bioresource Technology, 100(24), 6355-6361, 2009, doi:10.1016/j.biortech.2009.07.025.

[14] H.Y. Shin, S.H. Lee, J.H. Ryu, S.Y. Bae, "Biodiesel production from waste lard using supercritical methanol," The Journal of Supercritical Fluids, 61, 134-138, 2012, doi:10.1016/j.supflu.2011.09.009.

[15] I. Sarantopoulos, E. Chatzisymeon, S. Foteinis, T. Tsoutsos, "Optimization of biodiesel production from waste lard by a two-step transesterification process under mild conditions," Energy for Sustainable Development, 23, 110-114, 2014, doi:10.1016/j.esd.2014.08.005.

[16] P. Adewale, M. Dumont, M. Ngadi, "Enzyme-catalyzed synthesis and kinetics of ultrasonic assisted methanolysis of waste lard for biodiesel production," Chemical Engineering Journal, 284, 158-165, 2016, doi:10.1016/j.cej.2015.08.053.

[17] I.J. Stojković, M.R. Miladinović, O.S. Stamenković, I.B. Banković-Ilić, D.S. Povrenović, V.B. Veljković, "Biodiesel production by methanolysis of waste lard from piglet roasting over quicklime," Fuel, 182, 454-466, 2016, doi:10.1016/j.fuel.2016.06.014.

[18] C.B. Ezekannagha, C.N. Ude, O.D. Onukwuli, "Optimization of the methanolysis of lard oil in the production of biodiesel with response surface methodology," Egyptian Journal of Petroleum, 26(4), 1001-1011. 2017, doi:10.1016/j.ejpe.2016.12.004.

[19] Y. Pasae, L. Bulo, K. Tikupadang, T.T. Seno, "The use of super base cao from eggshells as a catalyst in the process of biodiesel production", Materials Science Forum, 967, 150-154, 2019, doi:10.4028/www.scientific.net/MSF.967.150.

[20] A.P.S. Dias, M. Ramos, "On the storage stability of $\mathrm{CaO}$ biodiesel catalyst. Hydration and carbonation poisoning," Journal of Environmental Chemical Engineering, 9(1), 104917, 2021, doi:10.1016/j.jece.2020.104917.

[21] F. Yaşar, "Biodiesel production via waste eggshell as a low-cost heterogeneous catalyst: Its effects on some critical fuel properties and comparison with CaO," Fuel, 255, 115828, 2019, doi:10.1016/j.fuel.2019.115828.

[22] Z. Helwani, M. Ramli, E. Saputra, B. Bahruddin, D. Yolanda, W. Fatra, G.M. Idroes, M. Muslem, T.M.I. Mahlia. R. Idroes, "Impregnation of $\mathrm{CaO}$ from eggshell waste with magnetite as a solid catalyst $\left(\mathrm{Fe}_{3} \mathrm{O}_{4} / \mathrm{CaO}\right)$ for transesterification of palm oil off-grade", Catalysts, 10(2), 1-13, 2020, doi:10.3390/catal10020164.

[23] M. Munir, M. Ahmad, M. Rehan, M. Saeed, S.S. Lam, A.S. Nizami, A. Waseem, S. Sultana, M. Zafar, "Production of high-quality biodiesel from novel non-edible Raphnus raphanistrum L. seed oil using copper modified montmorillonite clay catalyst," Environmental Research, 193, 110398, 2021, doi.org/10.1016/j.envres.2020.110398.

[24] M. Farooq, A. Ramli, A. Naeem, "Biodiesel production from low FFA waste cooking oil using heterogeneous catalyst derived from chicken bones," Renewable Energy, 76, 362-368, 2015, doi:10.1016/j.renene.2014.11.042.

[25] BS EN 14214:2012, Liquid Petroleum Products, Fatty Acid Methyl Esters (FAME) for use in Diesel Engines and Heating Applications, Requirements and Test Methods, 2012.

[26] EN ISO 3675:1998, Crude Petroleum and Liquid Petroleum Products Laboratory Determination of Density - Hydrometer Method, 1998.

[27] ASTM D445-19, Standard Test Method for Kinematic Viscosity of Transparent and Opaque Liquids (and Calculation of Dynamic Viscosity), ASTM International, West Conshohocken, PA, 2019, www.astm.org.

[28] ASTM D613-18a, Standard Test Method for Cetane Number of Diesel Fuel Oil, ASTM International, West Conshohocken, PA, 2018, www.astm.org.

[29] ASTM D240-19, Standard Test Method for Heat of Combustion of Liquid Hydrocarbon Fuels by Bomb Calorimeter, ASTM International, West Conshohocken, PA, 2019, www.astm.org.

[30] A. Bemani, Q. Xiong, A. Baghban, S. Habibzadeh, A.H. Mohammadi, M.H. Doranehgard, "Modeling of cetane number of biodiesel from fatty acid methyl ester (FAME) information using GA-, PSO-, and HGAPSO-LSSVM models", Renewable Energy, 150, 924-934, 2020, doi: 10.1016/j.renene.2019.12.086 